\title{
Short-term Mortality and Postoperative Complications of Abdominal Aortic Aneurysm Repair in Obese versus Non-obese Patients
}

\author{
Bo Zonneveld ${ }^{1}$, Duyen $\mathrm{Vu}^{1}$, Isabella Kardys' ${ }^{2}$, Bas M van Dalen ${ }^{2,3}$, Sanne M Snelder ${ }^{2,3, *}$ \\ 'Erasmus University Medical Centre, Rotterdam; ${ }^{2}$ Department of Cardiology, Thoraxcenter, Erasmus University Medical Centre, Rotterdam; ${ }^{3}$ Department of \\ Cardiology, Franciscus Gasthuis and Vlietland, Rotterdam, the Netherlands
}

Background: Obesity is a risk factor not only for abdominal aortic aneurysm (AAA) but also for complications after vascular surgery. This study was to determine the effect of obesity on short-term mortality and post-intervention complications after AAA repair.

Methods: A systematic review and meta-analysis were performed. A systematic search was performed in PubMed; the articles describing the differences in post-intervention complications after open or endovascular repair of an AAA between obese and non-obese patients were selected. The primary outcome was short-term mortality defined as in-hospital mortality or mortality within 30 days after AAA repair. The secondary outcomes were cardiac complications, pulmonary failure, renal failure, and wound infections. The meta-analysis was performed using OpenMeta.

Results: Four articles were included in the meta-analysis; these articles included 35,989 patients of which 10,917 (30.3\%) were obese. The meta-analysis showed no significant differences for short-term mortality (odds ratio [OR], 0.85; 95\% confidence interval [Cl], 0.69-1.04). Also, no significant difference was found in pulmonary failure (OR, 1.09; $95 \% \mathrm{Cl}, 0.85-1.42)$. However, obese patients were less likely to suffer from cardiac complications $(\mathrm{OR}, 0.73 ; 95 \% \mathrm{Cl}, 0.55-0.96)$. Nevertheless, there was a significantly higher risk of renal failure (OR, 1.16; $95 \% \mathrm{Cl}, 1.05-1.30)$ and wound infections (OR, 1.92; 95\% Cl, 1.55-2.38) in obese patients.

Conclusion: Obesity is not a risk factor for short-term mortality after AAA repair compared to non-obesity. Moreover, obese patients suffer less from cardiac complications than non-obese patients.

Key words: Obesity, Abdominal aortic aneurysm, Postoperative complications, Mortality
Received May 16, 2021

Reviewed September 10, 2021

Accepted October 8, 2021

*Corresponding author

Sanne M Snelder

(1)

https://orcid.org/0000-0003-3330-1400

Department of Cardiology, Thoraxcenter Erasmus University Medical Centre Rotterdam, Thoraxcenter's Gravendijkwal 230, 3015 CE Rotterdam، the Netherlands

Tel: +31-1-0704-2779

E-mail: s.snelder@erasmusmc.nl

\section{INTRODUCTION}

Obesity is a worldwide epidemic. The prevalence of obesity nearly tripled to 650 million individuals between 1975 and 2016. ${ }^{1}$ Obesity is defined as a body mass index $\geq 30 \mathrm{~kg} / \mathrm{m}^{2}$ by the World Health Organization and is a major risk factor for chronic diseases such as diabetes mellitus (DM), hypertension, cardiovascular diseases, and several cancers. ${ }^{1-3}$ Moreover, obesity is associated with a higher risk of abdominal aortic aneurysm (AAA)., Obesity is a risk factor for complications, e.g., wound infections, after surgery in general ${ }^{6}$ and, more specifically, after vascular surgery. ${ }^{7}$

The postoperative outcomes after AAA repair in obese patients undergoing open aneurysm repair (OAR) versus endovascular aneurysm repair (EVAR) have been previously described, ${ }^{8}$ but the effect of obesity on the outcomes after AAA repair is unknown. Because obesity is a risk factor for morbidity after vascular surgery, ${ }^{7}$ obesity may also be related to negative outcomes after AAA repair. If so, health care providers should be aware of the complications that 
are more likely to occur in these patients. Complications can then be diagnosed earlier, and treatment can be started earlier.

However, an obesity paradox has been described in which patients with obesity have a better prognosis than non-obese patients when diagnosed with various cardiovascular diseases ${ }^{9}$ or when undergoing invasive procedures such as percutaneous coronary interventions..$^{10}$ Therefore, the objective of this study was to determine the effect of obesity on short-term mortality and post-intervention complications after AAA repair.

\section{METHODS}

We conducted a systematic review according to the Preferred Reporting Items for Systematic Reviews and Meta-Analyses (PRISMA) guidelines. ${ }^{11}$

\section{Data sources and searches}

A systematic search was performed employing PubMed on December 11, 2019 using the following search query: ("Body mass index" [Mesh] OR "Overweight" [Mesh]) AND "Aortic aneurysm" [Mesh] AND ("Clinical Trial”[ptyp] OR "Epidemiologic Studies" $[$ Mesh $]$ ). To ensure that new articles not yet indexed with Mesh-term were included, a search for new articles published in 2019 was performed later. The data range was customized from January 1, 2019, to December 11, 2019, and the following query was used: ("Body mass index"[All Fields] OR "Overweight"[All Fields] OR "Obesity" [All Fields]) AND “Aortic aneurysm”[All Fields].

\section{Inclusion and exclusion criteria}

Two reviewers (BZ and DV) independently screened all identified studies for eligibility. Articles were required to be written in English and to describe the differences in post-intervention complications after OAR or EVAR between obese and non-obese patients. Articles were included or excluded based on the titles and abstracts. Last, full articles were reviewed and included if at least one of the following complications was discussed: short-term mortality, cardiac complications, pulmonary complications, renal complications, or wound infections. Articles were excluded if the data did not include the exact number of patients who experienced complications.

\section{Quality assessment}

The quality of the included studies was determined using the Newcastle-Ottawa scale (NOS) for cohort studies. Five or less points on the NOS were considered as poor quality. Articles were not excluded due to poor quality, but quality results were used to interpret the results of the meta-analysis.

\section{Outcomes}

The primary outcome was short-term mortality. Short-term mortality was defined as in-hospital mortality or mortality within 30 days after AAA repair. The secondary outcomes were cardiac complications (myocardial infarction, cardiac arrest, heart failure, or arrhythmias), pulmonary failure (unplanned reintubation, need for ventilation $>48$ hours after surgery, or in hospital pneumonia), renal failure (increased levels of plasma creatinine or dialysis use), and wound infections.

\section{Data extraction}

For each study the following data were collected: first author, year of publication, country, study type, number of included patients, gender of patients, number of obese and non-obese patients, definition of obesity, number of obese and non-obese patients undergoing different surgery type(s), number of ruptured AAAs, and number of obese and non-obese patients with DM. Moreover, the following outcome data were collected for both obese and nonobese patients: short-term mortality, pulmonary failure, cardiac complications, renal failure, and wound infections. Absolute numbers were calculated by both authors when the collected data were given in percentages.

\section{Statistical analysis}

Proportions of patients diagnosed with postoperative complications in the obese and non-obese groups were calculated. Odds ratios (ORs) with 95\% confidence intervals (CIs) were calculated for each individual study using OpenMeta. Results were considered statistically significant if $P<0.05$ (two-sided). The meta-analysis was also performed using OpenMeta, and ORs were used as metric. The value of Cochran's $Q$ was used to evaluate heterogeneity between the included studies. Heterogeneity was defined as $P<0.1$ for the Cochran's $Q$ statistic. If heterogeneity was present, a ran- 
dom-effects model was applied; otherwise, a fixed-effects model was applied.

\section{RESULTS}

\section{Study selection}

A total of 124 articles were found; 82 articles were identified by the first search query, 45 by the second, and three in both. By screening the titles and the abstracts of the 124 articles, 115 articles were

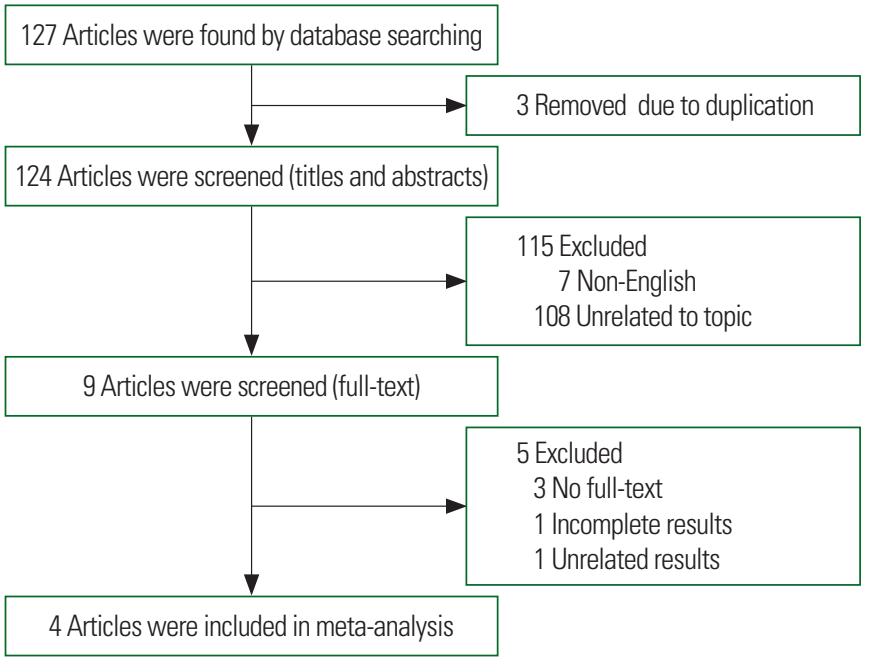

Figure 1. Flow diagram of identification and study selection. excluded. Another five articles were excluded after screening the full texts. Four articles met the selection criteria and were included in the meta-analysis (Fig. 1).

\section{Study characteristics}

All four studies were retrospective cohort studies and included 35,989 patients of which 10,917 (30.3\%) were obese. $28.1 \%$ of the obese patients versus $16.0 \%$ of the non-obese patients suffered from DM. Characteristics of the studies are shown in Tables 1 and 2 , and all studies discussed short-term mortality. ${ }^{12-15}$ Three articles discussed pulmonary failure and cardiac complications, ${ }^{13-15}$ and renal failure and wound infections were discussed in all four articles.

\section{Short-term mortality}

Short-term mortality occurred in 453 out of 35,989 patients (Ta-

Table 3. Percentages and ORs of short-term mortality in obese and non-obese patients undergoing AAA repair

\begin{tabular}{lccl}
\hline Author & Obese $(\mathrm{n}=10,917)$ & Non-obese $(\mathrm{n}=25,072)$ & \multicolumn{1}{c}{ OR (95\% CI) } \\
\hline Locham et al. $^{12}$ & $96(0.9)$ & $253(1.1)$ & $0.86(0.69-1.08)$ \\
${\text { Johnson et al. }{ }^{13}}$ & $19(3.2)$ & $70(4.4)$ & $0.74(0.46-1.19)$ \\
Jonker et al. $^{14}$ & $1(3.8)$ & 0 & $6.88(0.35-133.79)$ \\
Park et al. $^{15}$ & $3(1.9)$ & $11(2.3)$ & $0.82(0.24-2.78)$ \\
\hline
\end{tabular}

Values are presented as number (\%) unless otherwise indicated.

$\mathrm{OR}$, odds ratio; $\mathrm{AAA}$, abdominal aortic aneurysm; $\mathrm{Cl}$, confidence interval.

Table 1. Characteristics of the included studies

\begin{tabular}{|c|c|c|c|c|c|c|c|c|c|}
\hline \multirow{2}{*}{ Author } & \multirow{2}{*}{ Country } & \multirow{2}{*}{ Study type } & \multirow{2}{*}{ Population } & \multicolumn{3}{|c|}{ Sex } & \multicolumn{2}{|c|}{ Weight class } & \multirow{2}{*}{ NOS } \\
\hline & & & & Male & Female & Unknown & Obese & Non-obese & \\
\hline Locham et al. ${ }^{12}$ & USA & Retrospective cohort study & 33,082 & $26,450(80.0)$ & 6,630 (20.0) & $2(0.0)$ & $10,139(30.6)$ & $22,943(69.4)$ & 7 \\
\hline Johnson et al. ${ }^{13}$ & USA & Retrospective cohort study & 2,201 & 2,187 (99.4) & $14(0.6)$ & & $595(27.0)$ & $1,606(73.0)$ & 8 \\
\hline Jonker et al. ${ }^{14}$ & USA & Retrospective cohort study & 80 & $77(96.0)$ & $3(4.0)$ & & $26(32.5)$ & $54(67.5)$ & 5 \\
\hline Park et al. ${ }^{15}$ & USA & Retrospective cohort study & 626 & $502(80.2)$ & $124(19.8)$ & & $157(25.1)$ & $469(74.9)$ & 4 \\
\hline
\end{tabular}

Values are presented as number (\%).

NOS, Newcastle-Ottawa scale.

Table 2. Prevalence of obesity in the included studies

\begin{tabular}{|c|c|c|c|c|c|c|c|c|}
\hline Author & $\begin{array}{c}\text { Definition of } \\
\text { obesity }\end{array}$ & $\begin{array}{l}\text { Obesity } \\
\text { OAR (\%) }\end{array}$ & $\begin{array}{c}\text { Obesity } \\
\text { EVAR (\%) }\end{array}$ & $\begin{array}{c}\text { Non-obesity } \\
\text { OAR }(\%)\end{array}$ & $\begin{array}{l}\text { Non-obesity } \\
\text { EVAR }(\%)\end{array}$ & $\begin{array}{l}\text { Ruptured } \\
\text { AAA }(\%)\end{array}$ & $\begin{array}{l}\text { DM in obese } \\
\text { patients }\end{array}$ & $\begin{array}{c}\text { DM in non-obese } \\
\text { patients }\end{array}$ \\
\hline Locham et al. ${ }^{12}$ & $\mathrm{BMl} \geq 30 \mathrm{~kg} / \mathrm{m}^{2}$ & 17.3 & 82.7 & 20.1 & 79.9 & 0.0 & $2,864(28.2)$ & $3,665(16.0)$ \\
\hline Johnson et al. ${ }^{13}$ & $\mathrm{BMl} \geq 30 \mathrm{~kg} / \mathrm{m}^{2}$ & 49.6 & 50.4 & 55.5 & 45.5 & 3.1 & $155(26.1)$ & 252 (15.7) \\
\hline Jonker et al. ${ }^{14}$ & $\mathrm{BMI} \geq 30 \mathrm{~kg} / \mathrm{m}^{2}$ & 0.0 & 100.0 & 0.0 & 100.0 & 0.0 & $12(46.2)$ & $12(22.2)$ \\
\hline Park et al. ${ }^{15}$ & $\mathrm{BMI} \geq 30 \mathrm{~kg} / \mathrm{m}^{2}$ & 65.0 & 35.0 & 64.2 & 35.8 & 0.0 & $33(21.0)$ & 72 (15.4) \\
\hline
\end{tabular}

Values are presented as number (\%) unless otherwise indicated.

OAR, open aneurysm repair; EVAR, endovascular aneurysm repair; AAA, abdominal aortic aneurysm; DM, diabetes mellitus; BMl, body mass index. 
Studies

Locham et al. 2018

Johnson et al. 2010

Jonker et al. 2009

Park et al. 2011

Overall $\left(I^{2}=\mathrm{NA}, \mathrm{P}=0.52\right)$

$\begin{array}{llcc}\text { Estimate (95음 CI) } & \text { Ev/Trt } & \text { Ev/Ctrl } \\ 0.86(0.69, \quad 1.08) & 96 / 10139 & 253 / 22943 \\ 0.74(0.46, \quad 1.19) & 19 / 595 & 70 / 1606 \\ 6.88(0.35,133.79) & 1 / 26 & 0 / 54 \\ 0.82(0.24, & 2.78) & 3 / 157 & 11 / 469\end{array}$

$0.85(0.69,1.04) \quad 119 / 10917334 / 25072$

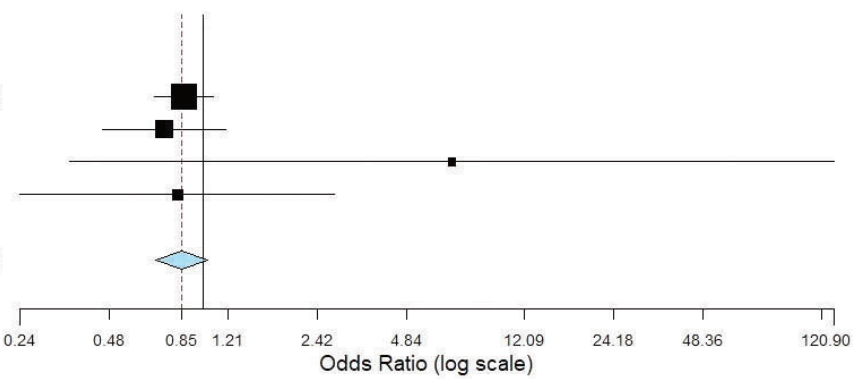

Figure 2. Forest plot of short-term mortality in obesity patients versus non-obese patients. Cl, confidence interval; Ev, events; Trt, treatment group; Ctrl, control group; NA, not available.

ble 3). A total of 119 obese patients (1.1\%) and 334 non-obese patients $(1.3 \%)$ died. Three out of the four studies showed that obese patients had a tendency towards a lower short-term mortality. However, none of these findings were statistically significant. No significant heterogeneity was found among the studies; therefore, a fixedeffects model was used for the meta-analysis $(P=0.52)$. Fig. 2 shows that the OR for the total population was 0.85 (95\% CI, 0.69-1.04; $P=0.10)$.

\section{Pulmonary failure}

Pulmonary failure was discussed in three out of the four articles (Table 4) and was reported in 333 patients. A total of 94 obese patients $(12.1 \%)$ and 239 non-obese patients (11.2\%) were diagnosed with pulmonary failure after AAA repair. None of the articles showed a significant difference between groups. There was no significant heterogeneity among the studies; therefore, a fixed-effects model was used for the meta-analysis $(P=0.27)$. Fig. 3A shows the metaanalysis with an OR of 1.09 (95\% CI, 0.85-1.42; $P=0.50)$.

\section{Cardiac complications}

Three of the four articles discussed cardiac complications (Table 4). These were reported in 298 patients of which 62 (8.0\%) were obese and 236 (11.1\%) were non-obese. All articles found a tendency towards fewer cardiac complications in obese patients compared to non-obese patients, but none of the results were statistically significant. Again, the fixed-effect model was applied for the meta-analysis because there was no heterogeneity among the studies $(P=0.94)$. The meta-analysis showed a significant difference in cardiac complications between obese and non-obese patients. These were significantly more frequent in the non-obese group. Fig. 3B shows
Table 4. Percentages and ORs of diagnoses with post-intervention complications in obese and non-obese patients undergoing AAA repair

\begin{tabular}{|c|c|c|c|}
\hline Author & Obese & Non-obese & OR $(95 \% \mathrm{Cl})$ \\
\hline \multicolumn{4}{|l|}{ Pulmonary failure } \\
\hline Johnson et al. ${ }^{13}$ & $65(10.9)$ & $181(11.3)$ & $0.97(0.72-1.30)$ \\
\hline Jonker et al..$^{14}$ & $3(11.5)$ & $4(7.4)$ & $1.67(0.32-8.64)$ \\
\hline Park et al. ${ }^{15}$ & $26(16.6)$ & $54(11.5)$ & $1.57(0.92-2.70)$ \\
\hline \multicolumn{4}{|c|}{ Cardiac complication } \\
\hline Johnson et al. ${ }^{13}$ & $33(5.5)$ & $117(7.3)$ & $0.76(0.52-1.11)$ \\
\hline Jonker et al. ${ }^{14}$ & 0 & $1(1.9)$ & $0.70(0.04-13.52)$ \\
\hline Park et al. ${ }^{15}$ & $29(18.5)$ & $118(25.2)$ & $0.69(0.45-1.06)$ \\
\hline \multicolumn{4}{|l|}{ Renal failure } \\
\hline Locham et al..$^{12}$ & $504(5.0)$ & $998(4.3)$ & $1.15(1.03-1.29)$ \\
\hline Johnson et al. ${ }^{13}$ & $32(5.4)$ & $63(3.9)$ & $1.42(0.90-2.26)$ \\
\hline Jonker et al. ${ }^{14}$ & $1(3.8)$ & $1(1.9)$ & $2.43(0.11-44.07)$ \\
\hline Park et al. ${ }^{15}$ & $10(6.4)$ & $31(6.6)$ & $0.96(0.46-1.20)$ \\
\hline \multicolumn{4}{|l|}{ Wound infection } \\
\hline Locham et al. $^{12}$ & $123(1.2)$ & $166(0.7)$ & $1.76(1.37-2.26)$ \\
\hline Johnson et al. ${ }^{13}$ & $50(8.4)$ & $67(4.2)$ & $2.32(1.52-3.52)$ \\
\hline Jonker et al. ${ }^{14}$ & 0 & $1(1.9)$ & $0.70(0.04-13.52)$ \\
\hline Park et al. ${ }^{15}$ & $3(1.9)$ & $1(0.2)$ & $14.43(1.50-139.18)$ \\
\hline
\end{tabular}

Values are presented as number (\%) unless otherwise indicated.

$\mathrm{OR}$, odds ratio; $\mathrm{AAA}$, abdominal aortic aneurysm; $\mathrm{Cl}$, confidence interval.

that the OR was $0.73(95 \% \mathrm{CI}, 0.55-0.96 ; P=0.03)$.

\section{Renal failure}

All four articles discussed renal failure after surgery (Table 4); renal failure was reported in 1,640 patients of which 547 (5.0\%) were obese and 1,093 (4.4\%) were non-obese. Three of the four articles showed that renal failure occurred more often in obese patients than in non-obese patients. However, only one of these studies demonstrated a significant difference. A fixed-effects model was used for the meta-analysis $(P=0.76)$, and the meta-analysis (Fig. 3C) showed a significant difference in occurrence of renal failure between obese 
Studies

Johnson et al. 2010

Jonker et al. 2009

Park et al. 2011

Overall $\left(\mathrm{I}^{2}=\mathrm{NA}, \mathrm{P}=0.27\right)$

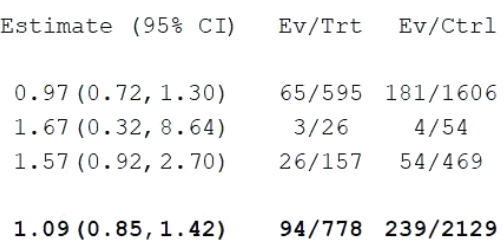

$1.09(0.85,1.42)$

$94 / 778 \quad 239 / 2129$

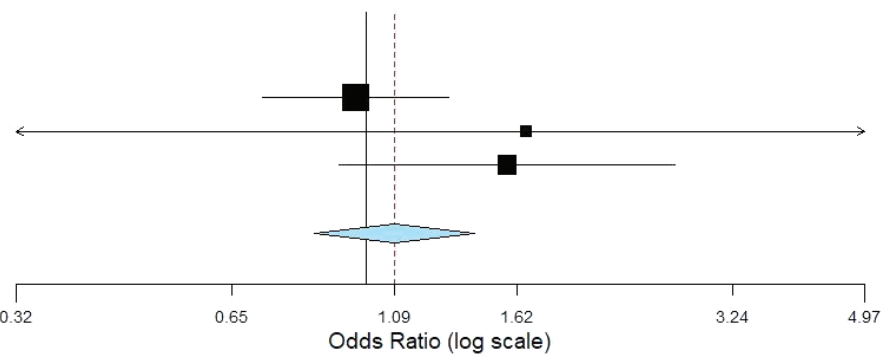

A

Studies

Johnson et al. 2010

Jonker et al. 2009

Park et al. 2011

Overall $\left(I^{2}=\mathrm{NA}, \mathrm{P}=0.94\right)$

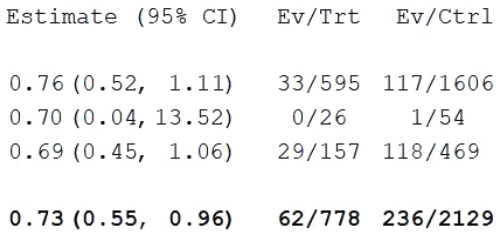

$0.73(0.55,0.96)$

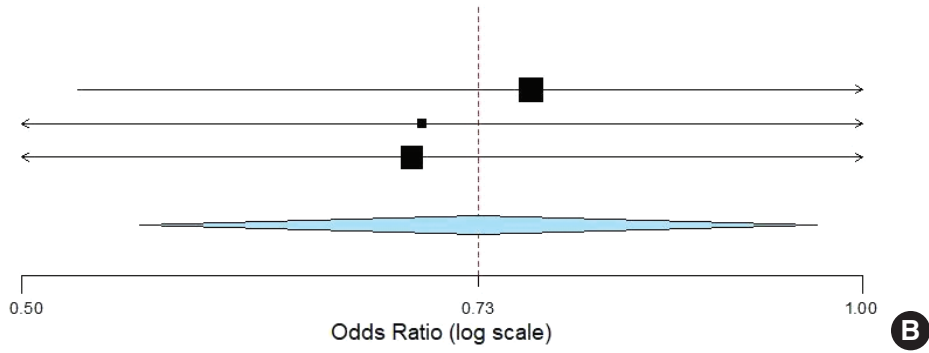

Studies

Locham et al. 2018

Johnson et al. 2010

Jonker et al. 2009

Park et al. 2011

Overall $\left(I^{2}=\mathrm{NA}, \mathrm{P}=0.76\right)$

Studies

Locham et al. 2018

Johnson et al. 2010

Jonker et al. 2009

Park et al. 2011

Overall $\left(I^{2}=\mathrm{NA}, \mathrm{P}=0.19\right)$

$\begin{array}{lcc}\text { Estimate }(95 \% \mathrm{CI}) & \text { Ev/Trt } & \text { Ev/Ctrl } \\ & & \\ 1.15(1.03,1.29) & 504 / 10139 & 998 / 22943 \\ 1.42(0.90,2.26) & 32 / 595 & 63 / 1606 \\ 2.24(0.11,44.07) & 1 / 26 & 1 / 54 \\ 0.96(0.46,2.00) & 10 / 157 & 31 / 469 \\ & & \\ 1.16(1.05,1.30) & \mathbf{5 4 7 / 1 0 9 1 7} & \mathbf{1 0 9 3 / 2 5 0 7 2}\end{array}$

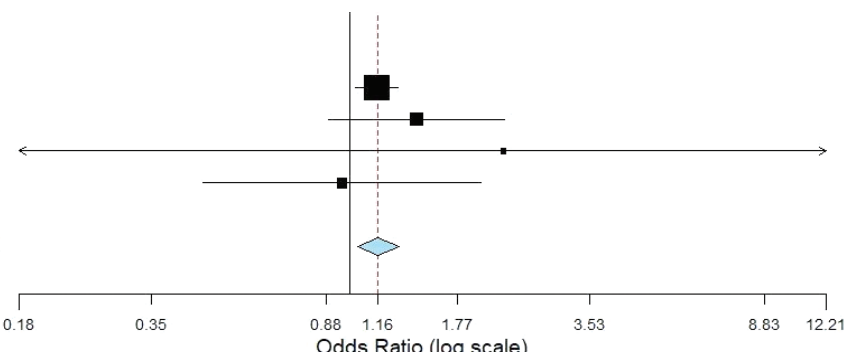

C

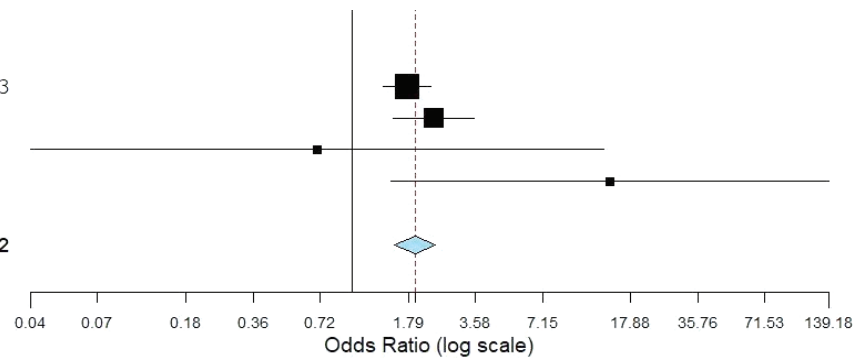

Figure 3. (A) Forest plot of diagnoses with pulmonary failure in obesity patients versus non-obese patients. (B) Forest plot of diagnoses with cardiac complications in obesity patients versus non-obese patients. (C) Forest plot of diagnoses with renal failure in obesity patients versus non-obese patients. (D) Forest plot of diagnoses with wound infections in obesity patients versus non-obese patients. Cl, confidence interval; Ev, events; Trt, treatment group; Ctrl, control group; NA, not available.

and non-obese patients. The OR was 1.16 (95\% CI, 1.05-1.30; $P=0.01)$.

\section{Wound infections}

All four articles discussed wound infections (Table 4). These occurred in 411 patients: 176 obese patients (1.6\%) and in 235 nonobese patients $(0.9 \%)$. Three of the four studies showed that obese patients had significantly more wound infections than non-obese patients. The fixed-effect model was again used $(P=0.14)$. In the meta-analysis, a significant difference in wound infections was found between the groups. Fig. 3D shows that the OR was 1.92 (95\% CI, $1.55-2.38 ; P<0.001)$.

\section{DISCUSSION}

A meta-analysis on short-term mortality and post-intervention complications after AAA repair in obese patients compared to nonobese patients was performed. The major finding of the study is 
that obesity does not appear to be a risk factor for short-term mortality after AAA repair compared to non-obesity. Obesity is also not a risk factor for postoperative pulmonary failure. Moreover, obese patients suffer less from cardiac complications than non-obese patients. However, obesity does appear to be a risk factor for both postoperative renal failure and wound infections.

The obesity paradox is that obese patients with several diseases, such as cardiovascular disease and cancer, have a better prognosis than non-obese patients. ${ }^{9,16}$ The mechanism through which this paradox functions is most likely multifactorial. ${ }^{17}$ For example, obese patients have a higher lean mass, including total body water, and skeletal muscle. When patients are diagnosed with a cardiovascular disease, increased lean mass causes higher cardiorespiratory fitness because of higher muscle diffusion capacity and mitochondrial respiration capacity at the skeletal muscle level. Higher cardiorespiratory fitness may be the reason for a better prognosis in these patients. ${ }^{9,18}$ Although the obesity paradox has been extensively described in a broad range of conditions ${ }^{19-21}$ and interventions, ${ }^{22,23}$ its applicability to AAA repair was unknown.

Three out of the four articles we have selected reported a (nonsignificant) trend towards a lower short-term mortality in obese patients. In the other study, only one person died; this patient was in the obesity group. ${ }^{14}$ Consistent with our results, Mariscalco et al. ${ }^{22}$ showed that overweight and obese patients undergoing cardiac surgery had lower in-hospital mortality compared to non-obese patients. The authors hypothesized that the survival benefit of obese patients may reflect worse outcomes of patients with either other severe diseases or underweight patients. These patients have decreased survival for reasons such as chronic diseases and cachexia. ${ }^{24}$ This may also be the most logical explanation for our finding of obesity not being a risk-factor for short-term mortality after AAA repair. We did find a lower chance of cardiac complications in obese patients; this is consistent with the obesity paradox. An explanation of this finding might be the higher cardiorespiratory fitness in obese patients with cardiovascular disease, as already described.

Our meta-analysis did not show a significant difference in pulmonary failure events. On the contrary, Eichenberger et al. ${ }^{25}$ showed that morbidly obese patients are more likely to suffer from atelectasis than non-obese patients after general anesthesia, even 24 hours after extubation. Anesthesia and paralysis can cause reduced end- expiratory lung volumes in morbidly obese patients leading to atelectasis and a fall in arterial oxygenation. ${ }^{26}$ An explanation for our results may be that we did not differentiate between obese and morbidly obese patients. Because of this, the worst outcomes of the morbidly obese patients might be nullified by the outcomes of the non-morbidly obese patients. We also did not differentiate between normal and underweight patients. The worst outcomes of obese patients might be outweighed by the worst outcomes of the underweight patients. Engel et al. ${ }^{27}$ showed that underweight patients suffered more from respiratory problems, and, therefore, required longer ventilation after coronary artery bypass graft surgery than normal weight patients.

Obese patients are more likely to suffer from postoperative renal failure after AAA repair than non-obese patients. Three of the four studies ${ }^{12-14}$ used in the meta-analysis described these results. However, one study ${ }^{15}$ described obese patients as having a lower chance of postoperative renal failure, but this study scored low on the quality assessment analysis. In line with our results, Moon et al. ${ }^{28}$ also showed that obesity is a risk factor for acute kidney injury (AKI) after coronary artery bypass grafting. Also, Billings et al. ${ }^{29}$ showed that obese patients have a greater risk of developing renal failure after cardiac surgery in general. These researchers found that the concentration of intraoperative F2-isoprostane, a marker for oxidative stress, may predict AKI after cardiac surgery and also suggested that obesity is associated with higher intraoperative concentrations of F2-isoprostane. Reducing the formation of F2-isoprostane could potentially reduce the risk of developing AKI in obese patients.

Finally, three out of the four studies ${ }^{12,13,15}$ and the meta-analysis showed that obese patients were significantly more likely to suffer from wound infections than non-obese patients. DM is a risk factor for surgical site infections for surgery in general, but especially for cardiac surgery. ${ }^{30} \mathrm{DM}$ also has a strong association with obesity; obese adults are seven times more likely to suffer from type 2 diabetes than non-obese adults. ${ }^{31}$ Consistent with this, DM was more common in obese patients than in non-obese patients in our study ( $28.1 \%$ vs. $16.0 \%)$. This association may be the reason that obese patients suffer more from wound infections than non-obese patients. Also, Rahmanian et al. ${ }^{32}$ showed that obese patients are at significantly higher risk of developing wound infections after coronary bypass 
grafting or valve surgery. This group also mentioned that the patients who had wound infections had a higher rate of other infections, e.g., gastrointestinal complications and renal failure, and increased mortality. Therefore, in obese patients, the prevention, diagnosis, and early treatment of wound infections require emphasis.

\section{Limitations}

This study included a large patient population and contributed to the knowledge base concerning the obesity paradox. However, a limitation of this study is that we did not distinguish between the two different types of surgery as we were only interested in the effect of obesity on AAA repair. However, Saedon et al. ${ }^{8}$ had previously determined that EVAR is superior to OAR in obese patients. Also, corrections were not made for differences between elective and emergent surgeries; this could have influenced the primary outcome. ${ }^{33}$ Another limitation is the small number of articles in this meta-analysis, and some of these articles did not describe the different subgroups of obesity. Therefore, subgroup analyses could not be made. Finally, quality assessment was performed using the NOS. Two of the four studies scored five or lower on the quality assessment. ${ }^{14,15}$ These two studies included the lowest number of patients. However, these studies could have influenced the final conclusions on shortterm mortality and other postoperative complications.

The obesity paradox appears to apply to obesity patients undergoing AAA repair. Although the underlying mechanism remains to be elucidated, this finding underlines that judgement on operability and the ability to intervene in obese patients should be based on a holistic approach considering all available patient data without overestimating potential harmful effects of obesity.

\section{CONFLICTS OF INTEREST}

The authors declare no conflict of interest.

\section{AUTHOR CONTRIBUTIONS}

Study concept and design: BZ and DV; acquisition of data: BZ and DV; analysis and interpretation of data: $\mathrm{BZ}$ and DV; drafting of the manuscript: $\mathrm{BZ}$ and DV; critical revision of the manuscript: SMS, IK, and, BMD; statistical analysis: $\mathrm{BZ}$ and $\mathrm{DV}$; administra- tive, technical, or material support: SMS, IK, and, BMD; and study supervision: SMS and BMD.

\section{REFERENCES}

1. World Health Organization. Obesity and overweight [Internet]. Geneva: World Health Organization; 2018 [cited 2020 Jan 14]. Available from: https://www.who.int/en/news-room/ fact-sheets/detail/obesity-and-overweight

2. GBD 2015 Obesity Collaborators, Afshin A, Forouzanfar MH, Reitsma MB, Sur P, Estep K, et al. Health effects of overweight and obesity in 195 countries over 25 Years. N Engl J Med 2017; 377:13-27.

3. Seo MH, Kim YH, Han K, Jung JH, Park YG, Lee SS, et al. Prevalence of obesity and incidence of obesity-related comorbidities in Koreans based on National Health Insurance Service Health Checkup Data 2006-2015. J Obes Metab Syndr 2018;27:46-52.

4. Golledge J, Clancy P, Jamrozik K, Norman PE. Obesity, adipokines, and abdominal aortic aneurysm: health in men study. Circulation 2007;116:2275-9.

5. Wang L, Djousse L, Song Y, Akinkuolie AO, Matsumoto C, Manson JE, et al. Associations of diabetes and obesity with risk of abdominal aortic aneurysm in men. J Obes 2017;2017: 3521649.

6. Bamgbade OA, Rutter TW, Nafiu OO, Dorje P. Postoperative complications in obese and nonobese patients. World J Surg 2007;31:556-60.

7. Galyfos G, Geropapas GI, Kerasidis S, Sianou A, Sigala F, Filis $\mathrm{K}$. The effect of body mass index on major outcomes after vascular surgery. J Vasc Surg 2017;65:1193-207.

8. Saedon M, Mt-Isa S, Saratzis A, Leung E, Mahmood A. Outcome of open versus endovascular abdominal aortic aneurysm repair in obese patients: a systemic review and meta-analysis. Int Angiol 2015;34:9-15.

9. Carbone S, Canada JM, Billingsley HE, Siddiqui MS, Elagizi A, Lavie CJ. Obesity paradox in cardiovascular disease: where do we stand? Vasc Health Risk Manag 2019;15:89-100.

10. Wolny R, Maehara A, Liu Y, Zhang Z, Mintz GS, Redfors B, et al. The obesity paradox revisited: body mass index and 
-long-term outcomes after PCI from a large pooled patientlevel database. EuroIntervention 2020;15:1199-208.

11. Liberati A, Altman DG, Tetzlaff J, Mulrow C, Gøtzsche PC, Ioannidis JP, et al. The PRISMA statement for reporting systematic reviews and meta-analyses of studies that evaluate health care interventions: explanation and elaboration. J Clin Epidemiol 2009;62:e1-34.

12. Locham S, Rizwan M, Dakour-Aridi H, Faateh M, Nejim B, Malas M. Outcomes after elective abdominal aortic aneurysm repair in obese versus nonobese patients. J Vasc Surg 2018;68: 1696-705.

13. Johnson ON 3rd, Sidawy AN, Scanlon JM, Walcott R, Arora S, Macsata RA, et al. Impact of obesity on outcomes after open surgical and endovascular abdominal aortic aneurysm repair. J Am Coll Surg 2010;210:166-77.

14. Jonker FH, Schlösser FJ, Dewan M, Huddle M, Sergi M, Dardik A, et al. Influence of obesity on in-hospital and midterm outcomes after endovascular repair of abdominal aortic aneurysm. J Endovasc Ther 2009;16:302-9.

15. Park B, Dargon P, Binette C, Babic B, Thomas T, Divinagracia $\mathrm{T}$, et al. Obesity is not an independent risk factor for adverse perioperative and long-term clinical outcomes following open AAA repair or EVAR. Vasc Endovascular Surg 2011;45:607-13.

16. Li S, Wang Z, Huang J, Fan J, Du H, Liu L, et al. Systematic review of prognostic roles of body mass index for patients undergoing lung cancer surgery: does the 'obesity paradox' really exist? Eur J Cardiothorac Surg 2017;51:817-28.

17. Elagizi A, Kachur S, Lavie CJ, Carbone S, Pandey A, Ortega FB, et al. An overview and update on obesity and the obesity paradox in cardiovascular diseases. Prog Cardiovasc Dis 2018; 61:142-50.

18. Lavie CJ, De Schutter A, Patel DA, Romero-Corral A, Artham SM, Milani RV. Body composition and survival in stable coronary heart disease: impact of lean mass index and body fat in the "obesity paradox". J Am Coll Cardiol 2012;60:1374-80.

19. Angerås $\mathrm{O}$, Albertsson $\mathrm{P}$, Karason $\mathrm{K}$, Råmunddal T, Matejka G, James S, et al. Evidence for obesity paradox in patients with acute coronary syndromes: a report from the Swedish Coronary Angiography and Angioplasty Registry. Eur Heart J 2013; 34:345-53.
20. Badheka AO, Rathod A, Kizilbash MA, Garg N, Mohamad T, Afonso L, et al. Influence of obesity on outcomes in atrial fibrillation: yet another obesity paradox. Am J Med 2010;123: 646-51.

21. Oga EA, Eseyin OR. The obesity paradox and heart failure: a systematic review of a decade of evidence. J Obes 2016;2016: 9040248.

22. Mariscalco G, Wozniak MJ, Dawson AG, Serraino GF, Porter $\mathrm{R}$, Nath $\mathrm{M}$, et al. Body mass index and mortality among adults undergoing cardiac surgery: a nationwide study with a systematic review and meta-analysis. Circulation 2017;135:850-63.

23. Mullen JT, Moorman DW, Davenport DL. The obesity paradox: body mass index and outcomes in patients undergoing nonbariatric general surgery. Ann Surg 2009;250:166-72.

24. Preston SH, Stokes A. Obesity paradox: conditioning on disease enhances biases in estimating the mortality risks of obesity. Epidemiology 2014;25:454-61.

25. Eichenberger A, Proietti S, Wicky S, Frascarolo P, Suter M, Spahn DR, et al. Morbid obesity and postoperative pulmonary atelectasis: an underestimated problem. Anesth Analg 2002;95:1788-92.

26. Reinius H, Jonsson L, Gustafsson S, Sundbom M, Duvernoy $\mathrm{O}$, Pelosi P, et al. Prevention of atelectasis in morbidly obese patients during general anesthesia and paralysis: a computerized tomography study. Anesthesiology 2009;111:979-87.

27. Engel AM, McDonough S, Smith JM. Does an obese body mass index affect hospital outcomes after coronary artery bypass graft surgery? Ann Thorac Surg 2009;88:1793-800.

28. Moon H, Lee Y, Kim S, Kim DK, Chin HJ, Joo KW, et al. Differential signature of obesity in the relationship with acute kidney injury and mortality after coronary artery bypass grafting. J Korean Med Sci 2018;33:e312.

29. Billings FT 4th, Pretorius M, Schildcrout JS, Mercaldo ND, Byrne JG, Ikizler TA, et al. Obesity and oxidative stress predict AKI after cardiac surgery. J Am Soc Nephrol 2012;23: 1221-8.

30. Martin ET, Kaye KS, Knott C, Nguyen H, Santarossa M, Evans $\mathrm{R}$, et al. Diabetes and risk of surgical site infection: a systematic review and meta-analysis. Infect Control Hosp Epidemiol 2016;37:88-99. 
31. Abdullah A, Peeters A, de Courten M, Stoelwinder J. The magnitude of association between overweight and obesity and the risk of diabetes: a meta-analysis of prospective cohort studies. Diabetes Res Clin Pract 2010;89:309-19.

32. Rahmanian PB, Adams DH, Castillo JG, Chikwe J, Bodian CA, Filsoufi F. Impact of body mass index on early outcome and late survival in patients undergoing coronary artery bypass grafting or valve surgery or both. Am J Cardiol 2007;100: $1702-8$.

33. Cota AM, Omer AA, Jaipersad AS, Wilson NV. Elective versus ruptured abdominal aortic aneurysm repair: a 1-year costeffectiveness analysis. Ann Vasc Surg 2005;19:858-61. 